\title{
The Psychology of Literacy: New Developments
}

\author{
José Morais, PAUlo Ventura, \\ CHOTIGA PATTAMADILOK \& RÉGINE KOLINSKY
}

\begin{abstract}
In this paper we begin by addressing the concept of literacy, which for us is "the ensemble of representations and processes that an individual acquires as an obligatory and direct consequence of learning to read and write", and distinguish it from other conceptions that can be found in the literature. In the remaining of the paper we discuss some of the most recent developments in the psychology of literacy: (i) the occurrence of language differences in the progressive mastery of the orthographic code; (ii) the neural basis of written word identification; and (iii) the consequences of literacy on spoken word identification.
\end{abstract}

\section{Definitions of literacy and of reading and writing}

The concept of literacy is not attributed the same meaning by everybody. Therefore, it feels necessary to begin by specifying what we think this term should refer to.

In our view, which we share with many other colleagues, literacy is "the ensemble of representations and processes that an individual acquires as an obligatory and direct consequence of learning to read and write" (Morais \& Kolinsky, 2005).

In a simpler way, it can also be said, with for example Gough (1995), that literacy is the ability to read and write. The two definitions are compatible with each other. The difference between them is essentially the following. By referring to an ensemble of representations and processes, we focus on competence or cognitive capacity; while, by presenting literacy as the ability to read and write, we emphasize the behavioral expression of competence and 
provide an operational definition of the literacy concept. Indeed, a full psychological account requires both the mental and the behavioral levels of description.

It is worth noting that, in the cognitive definition, the knowledge that is specifically contemplated is the one acquired "as an obligatory and direct consequence of learning to read and write". In other words, we exclude from the concept of literacy all knowledge that, being acquired through the use of the literacy abilities, is not inherent to these abilities.

To clarify this question, let us consider the following argument. Everyone would agree that we were already literate persons before we began studying psychological sciences. We certainly learned many things about the mind from what we have read; but this knowledge is not part of our intrinsic literacy competence. We may have developed also some thinking strategies from our reading of scientific texts; but these thinking strategies were not related in any necessary or sufficient way to the fact that we were able to read. We could have acquired those strategies just by listening to scientific talks, and actually we benefited from both reading and listening.

The only component of our literacy competence that we acquired by studying psychological sciences is a number of orthographic representations of words that we previously ignored and that can now be activated automatically in our mind. But these particular orthographic representations are not, as such, what cognitive science is supposed to describe and explain. All the individual orthographic lexicons are somewhat different. What we should attempt to describe and explain is not each individual orthographic lexicon, but the nature of the corresponding representations, the way they are formed, and how they intervene in word processing.

In the general literature, the concept of literacy is sometimes used to refer to the whole corpus of knowledge that is acquired and consolidated through the exercise of the reading and writing abilities. For example, Winchester (1985, p. 48) distinguished high-grade literacy ("what university disciplines are all about") from elementary literacy ("being able to read and write in ordinary ways"). In this sense, to be literate becomes synonymous of to be educated (in French, the educated person is called "lettré", antonym of ignorant).

We must admit that the definition of literacy that we have been arguing for is considered as too narrow by many cognitive psycholinguists, who propose "an extended functional definition" (Rayner, Foorman, Perfetti, Pesetsky \& Seidenberg, 2001; cf. also PISA, 2000, 2003, 2006). For these authors, "literacy may be defined as including computer literacy, historical literacy, and scientific literacy, among others". This represents "an extension of basic (reading and writing) skill and skill to reasoning and discourse in a domain". The two main problems that this definition encounters is, first, the fact that the term literacy is extended to knowledge that may have not been acquired 
through reading or writing, and, second, that the extension of the concept leads to an ad infinitum fragmentation into rather different domains.

As previously stated, we do not adopt this sense of the term "literacy", and this for mainly three reasons. First, one needs a concept to refer to the knowledge that is inherent to being able to read and write. Second, it is more appropriate to refer to whole knowledge using the term "education" or even "culture". And, third, if one includes all knowledge acquired through literacy activities in the concept of literacy, to inquire into the cognitive consequences of becoming literate would be a non-sense.

In our opinion, reducing the concept of literacy to the specific knowledge involved in both reading and writing presents a further advantage. In the present state of the art, there is still, and regrettably, little concern with the interactions between reading and writing, both in the course of learning and in the skilled literate person. It is true that we know much more about reading than about writing, and more about writing than about their interactions, but this is one of the reasons why we need a psychology of literacy.

One of the arguments that lead some authors to refuse to consider literacy as the specific knowledge involved in reading and writing is the fact that literate and illiterate people may differ in terms of other abilities. According to Abadzi (2003, p. 17), "the difference between literates and illiterates does not just consist of a reading skill. Schooled people have nerve networks that the unschooled lack. These are related to memory, attention span, data use, and ultimately decision making".

However, accepting this argument would simply mean that we are unable to distinguish variables that are correlated in our societies. The confusion is obvious in the shift that the author operates from illiterates to unschooled. Indeed, literate people are usually schooled and illiterates are usually unschooled. But literacy and schooling are different variables, and we ought to distinguish them when, for instance, we try to specify the cognitive correlates of literacy (cf. Kolinsky, 1999; Morais \& Kolinsky, 2004). We accept the risk of being apostrophized as inhumans when we say that our scientific object is the psychology of literacy, not the psychology of literate people. Literate people are not just literate, they differ from illiterates on many other variables: they have been in school for many years, they are educated, they belong to middle or upper classes in terms of income, they may be on better health conditions on the average, etc.

Having presented our view of literacy, we should also give a definition of reading. According to Rayner et al. (2001, p. 34), "reading is getting meaning from print" and "learning to read is learning how to use the conventional forms of printed language to obtain meaning from words". This definition is simple and appropriate because it isolates, in the activity of reading, the processes that are reading-specific.

It implies that comprehension processes that take place in the course of reading but are not directly related to the processing of written words go 
beyond the proper ability of reading. Yet, the mentioned definition recognizes that reading is not merely to convert written forms into spoken language forms. The connections allowing the access from written words to the corresponding semantic representations are established during the process of learning to read and belong specifically to the reading system.

In the remaining of this article, we offer a brief description of some of the most recent developments in the psychology of literacy. Nevertheless, it is worth to remind that the identification of the written word was already a main topic of experimental work in the late XIX century, and that it became again so since the cognitive revolution that began half a century ago. The work that is described below is quite recent and it concerns three issues in which progress is being accomplished very quickly. These issues are the occurrence of language differences in the progressive mastery of the orthographic code; the neural basis of written word identification; and the consequences of literacy on language abilities, more particularly on spoken word identification.

\section{The occurrence of language differences in the progressive mastery of the orthographic code}

The alphabetic writing system is based on the representation of phonemes by individual letter or groups of letters, the graphemes. This is called the "alphabetic principle". To grasp this principle is a difficult task, because phonemes are not sounds or fragments of sounds, they are abstract phonological units. It is now largely accepted that children are not aware of these units until they begin learning to read and write in the alphabetic system. Since the 70's of the last century there has been much work on the importance of becoming aware of speech as a sequence of phonemes for succeeding the initial steps of learning alphabetic literacy.

For many years, less attention has been devoted to a further source of difficulty in learning to read. This is the necessity to acquire the orthographic code of the language. Whereas the alphabetic principle is universal in the sense that it applies to all languages written alphabetically, the orthographic code is relative to each language in particular.

For a particular language, the nucleus of its orthographic code is formed by the set of grapheme-phoneme correspondences (GPC, relevant for reading) and by the set of phoneme-grapheme correspondences (PGC, relevant for writing) of the code. These two sets of correspondences can be described by a system of rules, either simple or complex. The complex rules may be positional (they take the position of the grapheme or phoneme in the word into account) or contextual (they take the adjacent graphemes or phonemes into account). All these rules may be language-dependent, and, depending on language, too, there may be more or less exceptions to the rules.

Not all rules and exceptions are learned in the same way. Some are learned through direct and explicit instruction, others may be learned in an implicit 
way through the practice of reading. The acquisition of the orthographic code is thus the outcome of both instruction and practice.

Obviously, differences in the rhythm of acquisition of the orthographic code may be expected to occur between languages, all other factors being equivalent, depending on the degree of transparency or opacity of the orthographic code. In transparent orthographies, the correspondences between graphemes and phonemes are consistent, whereas in opaque orthographies the same grapheme may represent different phonemes in different words and the same phoneme may be represented by different graphemes, for contextual, morphological or even historical reasons.

A recent study has clearly demonstrated this influence. Seymour, Aro and Erskine, in collaboration with COST Action A8 network (2003), assessed letter knowledge, word reading, and pseudo-word reading in first-grade children, at the end of the school year, for 13 orthographies in 16 European countries. On letter knowledge, the mean percentage of correct responses was equal to or higher than $90 \%$ for all language groups. On word reading, scores were around or above $95 \%$ for transparent orthographies, like Spanish, Italian or German, $74 \%$ and $79 \%$ for Portuguese and French, respectively, which are less transparent (given that they contain more inconsistent correspondences as well as morphological influences on spelling), and 34\% for English, which presents the least transparent orthography. On pseudo-word reading, scores did not diverge largely from those observed on word reading: around $90 \%$ for the most transparent languages, $77 \%$ and $85 \%$ for Portuguese and French, and $29 \%$ for English.

The statistical analyses run on these scores showed that, among the variables examined, only the transparency of the orthographic code and, to a much smaller extent, syllabic complexity, played a significant role. Neither the age of instruction onset (5, 6 or 7 years) nor the lexical status of the items (words versus pseudo-words) did elicit significant effects.

Curiously, word reading was not better in Portuguese than in French. However, the Portuguese orthographic code is more transparent than the French one, given that French has a much greater number of digraphs or complex graphemes representing a single phoneme, allows more ways for spelling vocalic digraphs, and utilizes more graphemes to represent consonantal phonemes. Assuming that these differences have an impact on learning to read, the absence of an advantage of the Portuguese scores over the French ones, could be due, among other factors, to differences in social background, instruction method, pedagogical efficiency, or programmed benchmarks.

Seymour et al. indicate that samples for all languages other than English were all from non-deprived regions. However and unfortunately, they do not provide any information about the method of teaching, a factor that is of great impact on word reading, at least in grade one. This is especially disturbing 
when one knows that the phonic method is largely used in Germany and Italy, whereas in Portugal it is commonly said to have a weak place.

It is interesting to remark that the effect of the transparency / opacity dimension can be observed even in the skilled adult reader. In a study by Paulesu, McCrory, Fazio, Menoncello, Brunswick, Cappa, Cotelli, Cossu, Corte, Lorusso, Pesenti, Gallagher, Perani, Price, Frith \& Frith (2000), contrasting English and Italian, the Italian students were faster than their English pairs in naming both words and pseudo-words. It must be noted that while the Italian orthographic code has less than forty ways of representing the corresponding phonemes, the English orthographic code presents more than one thousand.

Thus, written words made of a more opaque orthographic code are more difficult to identify than written words made of a more transparent orthographic code. This may seem to be trivial. Much less trivial however is the idea that the transparency or opacity of the orthographic code may determine the nature or size of the sub-lexical units that are used by the reader to identify the written words. In particular, more opaque codes might lead the reader to use larger units than more transparent ones.

Ziegler, Perry, Jacobs and Braun (2001) tested the idea that readers of a language with a more opaque orthography tend to use larger sub-lexical units and that readers of a language with a more transparent orthography tend to use smaller units. They compared skilled readers of either English or German. They manipulated rime frequency to investigate the use of large units, and length or number of letters of the words and pseudo-words to investigate the use of small units. The results showed a larger effect of the frequency of the rime in English than in German, and a larger effect of length in German than in English. Thus, both predictions were confirmed.

Resort to the rime as a reading unit in the case of an opaque orthographic code like English is likely to be due to the fact that orthographic rimes have more stable pronunciations than either individual vowels or initial consonant-plus-vowel units, as demonstrated by Treiman, Mullennix, Bijeljac-Babic and Richmond-Welty (1995). The reading learning system is attracted by consistency. The units that, with reading experience, end up as the privileged ones are those that offer the greatest degree of consistency.

However, consistency is probably not the whole story. Interestingly, the length effect for German deviated somewhat from linearity. Indeed, the effect was largest between items of 4 and 5 letters. An inspection of the German material suggests that having to process consonantal clusters at the beginning of the letter sequence, i.e. CCV- rather than CV- bodies, might be largely responsible for the acceleration in the length effect observed for German. The role of orthographic complexity in word reading in the particular case of transparent codes deserves to be examined in a more systematic way.

A further important question about the influence of orthographic transparency versus opacity on the type of reading units concerns the learning 
process. Can the use of large units and of small units in the case of, respectively, opaque and transparent orthographies be an emergent property of associative implicit learning at whole-word level, or is it dependent on explicit instruction?

Hutzler, Ziegler, Perry, Wimmer and Zorzi (2004) first examined this question by training a connectionist learning model based on the backpropagation rule (cf. Plaut, McClelland, Seidenberg \& Patterson, 1996) on a corpus of about 1300 English and German words. Pseudo-words of 3 to 6 letters were used in the test phase. Results of this simulation did not fit the developmental trajectory of children. Contrary to the behavioral data, there was no difference in performance between languages at the beginning of learning, and the difference that was observed later on did not decrease.

Then, the authors used the two-layer associative network of Zorzi, Houghton and Butterworth (1998), which is based on learning by classical conditioning. Although the simulation and behavioral data are relatively similar at the end of learning, the model still failed to simulate the difference between languages at the initial steps of learning.

Finally, the authors introduced in the two-layer associative model an analytical pre-training, by which the 60 more current grapheme-phoneme associations were learned. At this pre-training, there was no learning of whole words. The results this time fitted the difference between languages. The analytical pre-training allowed word reading to be clearly superior in German compared to English at the initial steps of learning.

Two important conclusions follow from this study. First, the associative implicit learning models are unable to simulate the differences in learning to read between German and English unless they incorporate a simulation of previous learning based on the grapheme-phoneme correspondences. Second, German benefited to a much greater extent from this analytical learning than English.

One may infer from these differences and from the important role that word identification plays in text comprehension that, depending on language, some types of sub-lexical units are more useful than other units for text comprehension. But there is still not much work on this question.

To the best of our knowledge, Taft (2001) ran the only study to have addressed this hypothesis directly. The subjects, college students, readers of English, were classified into two groups according to their performance on text comprehension. Then they were submitted to a lexical decision test in which the items were presented with an internal blank space that they had to ignore: for example, PA NIC (division according to the principle of maximum onset) or PAN IC (division according to the principle of maximum coda). Maximum coda, or inclusion of the intermediate consonant at the end of the first syllable rather than at the beginning of the first one, characterizes what Taft calls the BOSS (for Basic Orthographic Syllable Structure) of polysyllabic words. It is worth recalling that, in English, contrary to the 
Romance languages, ambisyllabicity is widespread, so that the BOSS may be relevant only for the transcription of languages that present syllabic boundary ambiguities.

The results of this study showed that the best text comprehenders were both faster and more accurate in the case of division according to the principle of maximum coda whereas the opposite pattern characterized the poor text comprehenders. It is theoretically justified to interpret these results by saying that skilled readers of English identify written words faster and are therefore in better conditions to understand text if they usually segment polysyllabic words into units according to the principle of maximum coda. We guess this not to be the case for languages in which written words are processed in a more analytical way.

\section{The neural basis of written word identification}

In the last years there has been a remarkable effort to specify the neural basis of reading processes, particularly of written word identification. We believe that this research begins to provide very useful data as regards the functional architecture of word processing.

Several studies using either implanted electrodes or fMRI have found that some brain areas respond more to letters than to digits or faces (Allison, McCarthy, Nobre, Puce \& Belger, 1994; Polk, Stallcup, Aguirre, Alsop, D'Esposito, Detre \& Farah, 2002). A further study, using PET, showed the discrimination between letters and pseudo-letters to be associated to the activity of Brodmann area 37 in the left hemisphere (Garrett, Flowers, Absher, Fahey, Gage, Keyes, Porrino \& Wood, 2000). This area of the extrastriate cortex is lateral to an area called "visual word form area" (Warrington \& Shallice, 1980), which is activated by orthographic sequences. The French group led by Dehaene and Cohen proposed that visual lexical forms and more generally orthographic forms are represented in a region of the left fusiform gyrus defined by the Talairach coordinates $x=-43, y=-54$ and $z=-12$, with a standard deviation of only about half a centimeter (cf. McCandliss, Cohen \& Dehaene, 2003).

Studies using MEG have shown that the activation of the visual word form area takes place from 150 to 200 milliseconds after the onset of the letter sequence exposure (e.g., Tarkiainen, Helenius, Hansen, Cornelissen \& Salmelin, 1999). A large number of observations, mostly consistent, have contributed to specify the functions of this area.

First, the area is activated by both words and pseudo-words, but not by strings of consonants like "xjpqt" (Dehaene, Le Clec'h, Poline, LeBihan \& Cohen, 2002; Petersen, Fox, Snyder \& Raichle, 1990). Thus, it is not concerned by the processing of letters as such, but only by legal, orthotactically acceptable structures of letters. 
Second, the area is not activated by the auditory presentation of words and pseudo-words (Dehaene et al., 2002), which suggests that the processing of structures that would be strictly phonological does not concern it.

Third, physical modifications such as case (AGE - age - aGe) or font (age) do not affect the amplitude of its activation (Polk \& Farah, 2002; Dehaene, Naccache, Cohen, LeBihan, Mangin, Poline \& Rivière, 2001), suggesting that the knowledge represented in this area is not the knowledge of a physical form but of an abstract linguistic structure.

Fourth, its activation occurs even when, using masking techniques, the subject is unable to recognize the word presented (Dehaene et al., 2001). This suggests that the processing carried out in this area is not, or not necessarily, conscious.

Cohen and Dehaene (2004) have written an article that is both a review of the available data and a theoretical discussion. These authors remind us that reading poses particular problems to the visual system. Our word identification system has to compute an invariant representation from the visual input. It discards irrelevant variations such as differences in case or font or size (eight - EIGHT), and maintains very small details (eight - sight) that support different pronunciations and meanings. This functional specialization of the reading system does not result from the intrinsic characteristics of the visual system but from a learning process that is culturally determined. This learning process led to the fact that some visual neurons respond to " $\mathrm{A}$ " and "a" in the same way, but differently to "a" and "e".

Given that, according to the brain imagery data, these neurons tend to be grouped together in some fixed regions of the visual cortex, Cohen and Dehaene (2004) proposed that there is also reproducible localization. Thus, "whenever subjects read a word, a reproducible portion of the left occipitotemporal sulcus is activated and hosts functionally specialized circuits for letter and word recognition" (p. 468).

This hypothesis does not exclude an engagement of the same groups of neurons in other processes such as face or object identification (cf. Price \& Devlin, 2003). One must take into account that functional specialization for reading arises from partial preemption or "recycling" of the visual cortex (Dehaene, 2005). Therefore, the regional selectivity for word recognition is probably more relative than absolute, with some intermixing of selective groups of neurons, or with groups of neurons showing different degrees of responsiveness to different classes of stimuli.

Dehaene, Jobert, Naccache, Ciuciu, Poline, LeBihan, and Cohen (2004) measured brain activity during subliminal masked priming and found the mid-fusiform cortex to be composed of at least three functionally different sub-areas. In the posterior subpart there was indication of bilateral priming (reduction of activity) in the response to repetition of letters at the same absolute location, regardless of whether these letters were presented in the same word (reflet - REFLET) or in an anagram (reflet - TREFLE). This seems to be a sub-area of letter detection. In a somewhat more anterior subarea of the 
left hemisphere, priming was similar when the same word was repeated, even when shifted by one letter location (reflet* - *REFLET) so it was just displaced, and when a word was followed by its anagram (reflet - TREFLE). Thus, letters, or fragments of words, are represented in this area independently of location. Finally, in an even more anterior sub-area, priming tended to be larger for same words than for anagrams, suggesting that this third sub-area may be involved in word coding.

It must be emphasized that there is no innate module for written word processing. Functional specialization, reproducible localization and, perhaps, some relative selectivity are the outcome of a learning process that is made possible by the plasticity of the cortex and by the characteristics of the learning process.

Regarding plasticity, it is interesting to note that Polk and Farah (1998) obtained behavioral evidence suggesting that functional specialization can be altered by late experience, at adult age. The categorization effect consisting in detecting a letter faster when it is presented among digits than when it is presented among letters was absent in Canadian postal workers who, during their work, are constantly exposed to mixtures of letters and digits. This suggests that, after one has learned to read, keeping on reading might be necessary for maintaining functional specialization for reading. This is of course a strong hypothesis that requires, to be accepted, many more convergent data.

Regarding the characteristics of the learning process, it is now largely recognized that phonological decoding is a crucial mechanism for acquiring the orthographic representations of words. This notion is confirmed by several observations on the activation of the left mid-fusiform gyrus. Shaywitz, Shaywitz, Pugh, Fulbright, Constable, Mencl, Shankweiler, Liberman, Skudlarski, Fletcher, Katz, Marchione, Lacadie, Gatenby and Gore (2002) found a positive correlation between the amplitude of activation of this region and the level of performance in tests of phonological decoding in individuals aged 7 to 18 years, even when age was taken into account. Perhaps more convincingly, a phonological remediation program was found to lead to increased activity in several regions, including the visual word form area, in a group of 20 children who presented dyslexia (Temple, Deutsch, Poldrack, Miller, Tallal, Merzenich \& Gabrieli, 2003). These results, together with many other data from experimental psycholinguistics, support the idea that phonological processing plays an important role in the development of functional specialization for reading in the brain.

\section{The consequences of literacy on language abilities, more particularly on spoken word identification}

The consequences of literacy on language abilities may be examined in at least two ways. 
One way is to compare language abilities in illiterates and literate people of similar educational level. This control population is difficult to find, and the most accessible solution is to test ex-illiterates, or subjects who learned to read and write only recently, at adult age, out of normal school. Our group has presented reviews of this work in several texts (Morais \& Kolinsky, 2002, 2005) and we will only offer a very short summary. The other way of doing it is to look for indications of the influence of specific aspects of the literacy competence by carrying out some sort of between-item comparison on literate people.

The studies comparing illiterates to ex-illiterates have shown relatively small or absent effects of literacy on lexical semantics, on verbal memory, and on word or pseudo-word repetition. In contrast, there is a huge effect of literacy on grasping and conceptualizing speech as a sequence of phonemes and, therefore, on abilities that depend on phoneme awareness.

Note that it may be very interesting to look for the occurrence or not of a literacy effect on linguistic abilities that might be hypothesized to be at the origin of an anomaly in acquiring literacy. If, say, dyslexics are inferior to normal readers in some ability, this inferiority might be related to either a cause or an effect of their abnormally poor reading level. Then, showing that illiterates behave like normal readers in that particular ability would suggest that the dyslexics' inferiority in this ability might well be related to a determinant of their difficulties in learning to read.

In several studies, it has been found that dyslexics present some anomalies in speech perception, namely weaker signs of categorical perception than normal readers. Serniclaes, Sprenger-Charolles, Carré and Demonet (2001) and Serniclaes, Van Heghe, Mousty, Carré and Sprenger-Charolles (2004) observed that both poorer inter-category discrimination and better intra-category discrimination characterize dyslexics, compared to normal readers. This may lead to a serious difficulty in gaining conscious access to phoneme categories when children begin learning to read and write. Castro (1993) did not find a significant difference in the identification of consonants along voicing continua between illiterate and literate subjects.

Recently, Serniclaes, Ventura, Morais and Kolinsky (2005) found heterogeneous results for categorical perception using place of articulation. There was no difference between illiterate and literate subjects on discrimination, but the precision of the categorical boundary was poorer, on the average, among the illiterates. This would lead to hypothesize the following as regards the relation between dyslexia and the categorical perception of speech. On the one hand, the discrimination deficit displayed by dyslexics might indeed be a cause of dyslexia. On the other hand, learning to read and write might also have an effect on speech perception by rendering the categorical phonetic boundary more precise.

One particular aspect of the literacy competence, namely the knowledge of how words are written, has been shown to influence judgements about phonology and even the recognition of spoken words. 
Orthographic knowledge influences the explicit analysis of spoken words as shown, for example, by Ehri and Wilce's (1979) observation that subjects count an additional letter in "pitch" compared to "rich" due to the presence of the letter $t$ in the spelling of the first word. Also, as shown by Seidenberg and Tanenhaus (1979), auditory rhyme decisions depend on rime spelling. Correct same responses are faster when the word rimes are orthographically similar (toast-roast) than when they are not (toast-ghost), and correct different responses show the opposite result (faster for leaf-ref than for leaf-deaf). Furthermore, testing literate subjects in a task that requires blending the initial part of a word with the final part of another word, Ventura, Kolinsky, Brito-Mendes and Morais (2001) found opposite types of blend depending on spelling. There was a preference for a $\mathrm{C} / \mathrm{VC}$ blend when the spelling of the presented words ends with a consonant (bar-mel), but a preference for a $\mathrm{CV} / \mathrm{C}$ blend when the spelling ends with a mute e (cure-pele).

All these examples illustrate the influence that intensive practice on orthographic codes has on phonological intuitions. But orthographic knowledge has also an impact on the processes of spoken word recognition. Morais, Castro, Scliar-Cabral, Kolinsky, and Content (1987) reported what is probably the first illustration of this impact. In a spoken word recognition task using dichotic presentation, literate subjects made proportionally more errors on the initial consonant of the target word than illiterates, even when subgroups were equated for overall performance. This suggests that literate people tend to use an attentional mechanism focusing on the phonemic structure of the words.

Curiously, models of spoken word recognition (see, e.g. McClelland \& Elman, 1986; Luce, Pisoni \& Goldinger, 1990; Marslen-Wilson, 1989) have never included the possibility of an intervention of orthographic knowledge. It seems that now, on the basis of the evidence accumulated in the last few years, we should recognize this intervention.

Using the auditory lexical decision, Ziegler and Ferrand (1998) compared inconsistent French words (NOM is inconsistent because its rime can be spelled in multiple ways, for example N-ON, J-ONC, L-ONG, etc.) and words with rimes that are spelled only one way (RICHE has a consistent rime). The inconsistent words produced longer auditory lexical decision latencies and more errors than did the consistent words. Ventura, Morais, Pattamadilok and Kolinsky (2004) confirmed this effect for Portuguese (in this language, for instance, /-al/ is inconsistent, cf. CAL-CALE), and /-av/, always spelled with a silent "e", is consistent). Note that potential phonetic variability may occur on the final consonant depending on whether it is followed or not by the mute letter. However, this is not relevant for calculating the degree of consistency, because the counterpart of the grapheme is not the phonetic percept but the more abstract phoneme. In Portuguese, for example, the single " $\mathrm{r}$ " is pronounced and perceived quite differently before a vowel and before a consonant, but this contextual dependence has no functional consequence for 
discriminating between words; therefore, these two different " $r$ " share the same phonemic value. Phonetic differences that are not phonemic do not require different graphemes.

The orthographic consistency effect must occur relatively late in the recognition process. Several arguments can be adduced in favor of such a conclusion. First, if the influence of orthographic knowledge occurred at all stages of speech processing, then the consistency effect should be observed not only for words but also for pseudowords. Yet, in adult lexical decision, the consistency effect is restricted to words both in French (Ziegler \& Ferrand, 1998; but see Pattamadilok, Morais, Ventura \& Kolinsky, 2007) and in Portuguese (Ventura et al., 2004). Second, if the consistency effect were restricted to lexical involvement, then it should not be observed, or at least less so, in tasks, like shadowing, that tap earlier, pre-lexical, stages of processing and in which lexical representations are less involved than in lexical decision (e.g., Balota \& Chumbley, 1984). In accordance with this reasoning, adults exhibited no consistency effect in shadowing of either words or pseudowords (Pattamilok et al., 2007; Ventura et al., 2004; Ziegler, Ferrand \& Montant, 2004). Moreover, having compared two situations in which a shadowing response was made contingent upon either a lexical or a phonemic criterion, we found an effect of orthographic consistency only in the former situation (Ventura et al., 2004). So, there is clear evidence for both the involvement of orthographic knowledge in spoken word recognition and for its locus, which seems to be lexical processing.

Why are words with orthographically consistent rimes accessed to more rapidly than words with inconsistent rimes? In speech communication, the acoustic data in general do not specify word boundaries, contrary to the orthography, so that orthographic knowledge could be an aid to spoken word recognition. We could presumably test this hypothesis by looking for consistency orthographic effects at both internal and end points of the written representation of words.

A further question about this influence of graphophonological consistency on the recognition of spoken words concerns the automatic versus strategic nature of the processing involved. By strategic we do not mean conscious and intentional, but more generally flexible, i.e. controlled by task or contextual factors. Whether the intervention of rhyme orthographic representations in spoken word recognition is automatic or not was examined by Pattamadilok, Kolinsky, Ventura, Radeau and Morais (2007). Using a priming manipulation, more precisely of final overlap, under conditions aimed at reducing the impact of response biases and conscious strategies, we did not find any orthographic congruency effect from spoken word primes on spoken word targets in a shadowing task. More important, in lexical decision, an orthographic congruency effect occurred, but only when the processing environment reduced the prominence of phonological overlap, and thus led the lexical processing system of the participants to rely on word spelling. 
Thus, even assuming that orthographic representations are automatically activated, probably from the sublexical level of structure, in the course of speech processing, there ought to be limitations to the irrepressible intervention of those representations in this processing. We have indeed shown that the orthographic characteristics of a prime do not automatically influence the recognition of a subsequent word target, as in the mentioned study, an orthographic congruency effect only occurred in a particular context. However, the orthographic consistency effect has been shown to occur systematically with the kind of word materials that have been used. Verifying whether the latter effect is actually automatic or not in the literate adult is a challenge for future research.

\section{Conclusion}

The new developments in the psychology of literacy raise outstanding issues that are theoretically among the major ones for the comprehension of the systems involved in linguistic functioning. The cross-linguistic study of reading processes digs a deep distinction, with obviously applied implications, between the general and the code-specific competences of alphabetic readers. The investigation of the brain structures that support letter and word reading has already demonstrated their functional specificity, and the refinement of these methods may, in a very close future, converge with the behavioral approach to unveil more detailed aspects of processing. Finally, while in the past the recognition of spoken and written words was supposed to rely on separate systems, we are beginning to trace back the flows of information in and between the two lexical access systems, which actually do seem to operate in an integrated way.

\section{Acknowledgements}

A previous version of this paper was presented at the Conference on Language Acquisition held in Lisbon in June 2003 and organized by the Department of Linguistics of the University of Lisbon. The experiments reported in section 4 were supported by a grant from the Belgium French Community (ARC 06/11-342) and by a grant of Fundação para a Ciência e a Tecnologia - Ministério da Ciência, Tecnologia e Ensino Superior (Project PTDC / PSI / 66077 / 2006, "Cognitive consequences of literacy"). The third and the fourth authors are, respectively, Postdoctoral Researcher and Senior Research Associate of the Belgian Fonds de la Recherche Scientifique F.N.R.S. 


\section{References}

Abadzi, H. (2003) Improving adult literacy outcomes: Lessons from cognitive research for developing countries. Washington: World Bank.

Allison, T., McCarthy, G., Nobre, A., Puce, A., \& Belger, A. (1994) Human extrastriate visual cortex and the perception of faces, words, numbers and colors. Cerebral Cortex, 5, 544-554.

Balota, D.A., \& Chumbley, J.I. (1984) Are lexical decisions a good measure of lexical access? The role of word frequency on the neglected decision stage. Journal of Experimental Psychology: Human Perception and Performance, 10, 340-357.

Castro, S.L. (1993) Alfabetização e Percepção da fala [Alphabetization and speech perception]. Porto, Portugal: Instituto Nacional de Investigação Científica.

Cohen, L., \& Dehaene, S. (2004) Specialization within the ventral stream: the case for the visual word form area. NeuroImage, 22, 466-476.

Dehaene, S. (2005) Evolution of human cortical circuits for reading and arithmetic: The «neuronal recycling» hypothesis. In From monkey brain to human brain, (S. Dehaene, J.R. Duhamel, M. Hauser \& G. Rizzolatti, editors). Cambridge, Mass.: MIT Press.

Dehaene, S., Clec'h, G., Poline, J-B., LeBihan, D., \& Cohen, L. (2002) The visual word form area. A prelexical representation of visual words in the fusiform gyrus. NeuroReport, 13, 321-325.

Dehaene, S., Jobert, A., Naccache, L., Ciuciu, P., Poline, J-B., LeBihan, D., \& Cohen L. (2004) Letter binding and invariant recognition of masked words: Behavioral and neuroimaging evidence. Psychological Science, 15, 307-313.

Dehaene, S., Naccache, L., Cohen, L., LeBihan, F., Mangin, J.F., Poline, J-B., \& Rivière, D. (2001) Cerebral mechanisms of word masking and unconscious repetition priming. Nature Neuroscience, 4, 752-758.

Ehri, L.C., \& Wilce, L.S. (1979) Mnemonic value of orthography among beginning readers. Journal of Educational Psychology, 71, 26-40.

Garrett, A.S., Flowers, D.L., Absher, J.R., Fahey, F.H., Gage, H.D., Keyes, J.W., Porrino, L.J., \& Wood, F.B. (2000) Cortical activity related to accuracy of letter recognition. NeuroImage, 11, 111-123.

Gough, P. (1995) The New Literacy: caveat emptor. Journal of Research in Reading, $18,79-86$.

Hutzler, F., Ziegler, J.C., Perry, C., Wimmer, H., \& Zorzi, M. (2004) Do current connectionist learning models account for reading development in different languages? Cognition, 91, 273-296.

Kolinsky, R. (1999) Literacy and schooling: an often neglected but necessary distinction. In Investigando a linguagem: Ensaios em homenagem a Leonor Scliar-Cabral (L. Grimm Cabral \& J. Morais, editors), pp. 297-310. Florianópolis: Ed. Mulheres.

Luce, P.A., Pisoni, D.B., \& Goldinger, S.D. (1990) Similarity neighborhoods of spoken words. In Cognitive models of speech processing: Psycholinguistic and computational perspectives (G.T.M. Altmann, editor), pp. 142-147. Cambridge, MA: MIT Press.

Marslen-Wilson, W.D. (1989) Access and integration: Projecting sound onto meaning. In Lexical access and representation (W.D. Marslen-Wilson, editor) pp. 3-24. Cambridge, MA: Bradford Books. 
McCandliss, B.D., Cohen, L., \& Dehaene, S. (2003) The Visual Word Form Area: expertise for reading in the fusiform gyrus. Trends in Cognitive Science, 7, 293 -299 .

McClelland, J.L., \& Elman, J.L. (1986) The TRACE model of speech perception. Cognitive Psychology, 18, 1-86.

Morais, J., Castro, S.L., Scliar-Cabral, L., Kolinsky, R., \& Content, A. (1987) The effects of literacy on the recognition of dichotic words. Quarterly Journal of Experimental Psychology, 39A, 451-465.

Morais, J., \& Kolinsky, R. (2002) Literacy effects on language and cognition. In Pyschology at the turn of the millennium (L. Bäckman \& C. von Hofsten, editors), pp. 507-530. Psychology Press.

Morais, J., \& Kolinsky, R. (2004) The linguistic consequences of literacy. In Handbook of children's literacy (T. Nunes \& P. Bryant, editors), pp. 599-622. Dordrecht: Kluwer.

Morais, J., \& Kolinsky, R. (2005) Literacy and cognitive change. In The Science of Reading: a Handbook (M. Snowling \& Ch. Hulme, editors), pp. 188-204. Oxford: Blackwell.

Pattamadilok, C., Kolinsky, R., Ventura, P., Radeau, M., \& Morais, J. (2007) Orthographic representations in spoken word priming: No early automatic activations. Language and Speech, 50, 505-531.

Pattamadilok, C., Morais, J., Ventura, P., \& Kolinsky, R. (2007) The locus of the orthographic consistency effect in auditory word recognition: Further evidence from French. Language and Cognitive Processes, 22, 1-27.

Paulesu, E., McCrory, E., Fazio, F., Menoncello, L., Brunswick, N., Cappa, S.F., Cotelli, M., Cossu, G., Corte, F., Lorusso, M., Pesenti, S., Gallagher, A., Perani, D., Price, C., Frith, C.D., \& Frith, U. (2000) A cultural effect on brain function Nature Neuroscience, 3, 91-96.

Petersen, S.E., Fox, P.T., Snyder, A.Z., \& Raichle, M.E. (1990) Activation of extrastriate and frontal cortical areas by visual words and word-like stimuli. Science, 249, 1041-1044.

PISA (2000) Assessment of reading, mathematical and scientific literacy. http://www.pisa.oecd.org/pages/

PISA (2003) Learning for tomorrow' world. http://www.pisa.oecd.org/pages/

PISA (2006) Science competencies for tomorrow's world. http://www.pisa.oecd.org/pages/

Plaut, D.C., McClelland, J.L., Seidenberg, M.S., \& Patterson, K. (1996) Understanding normal and impaired word reading: computational principles in quasi-regular domains. Psychological Review, 103, 56-115.

Polk, T.A., \& Farah, M.J. (1998) The neural development and organization of letter recognition: Evidence from functional neuroimaging, computational modeling, and behavioral studies. Proceedings of the National Academy of Sciences of the USA, 95, 847-852.

Polk, T.A., \& Farah, M.L. (2002) Functional MRI evidence for an abstract, not perceptual, word-form area. Journal of Experimental Psychology: General, 131, 65-72.

Polk, T.A., Stallcup, M., Aguirre, G.K., Alsop, D.C., D’Esposito, M., Detre, J.A., \& Farah, M.J. (2002) Neural specialization for letter recognition. Journal of Cognitive Neuroscience, 14, 145-159. 
Price, C.J., \& Devlin, J.T. (2003) The myth of the visual word form area. Neuroimage, $19,473-481$.

Rayner, K., Foorman, B.R., Perfetti, C.A., et al. (2001) How psychological science informs the teaching of reading. Psychological Science, 31-74.

Seidenberg, M.S., \& Tanenhaus, M.K. (1979) Orthographic effects on rhyme monitoring. Journal of Experimental Psychology: Human Learning and Memory, $5,546-554$.

Serniclaes, W., Sprenger-Charolles, L., Carré, R., \& Demonet, J.-F. (2001) Perceptual discrimination of speech sounds in developmental dyslexia. Journal of Speech Language and Hearing Research, 44, 384-399.

Serniclaes, W., Van Heghe, S., Mousty, P., Carré, R., \& Sprenger-Charolles, L. (2004) Allophonic mode of speech perception in dyslexia. Journal of Experimental Child Psychology, 87, 336-361.

Serniclaes, W., Ventura, P., Morais, J., \& Kolinsky, R. (2005) Categorical perception of speech sounds in illiterate adults. Cognition, 98, B35-B44.

Seymour, P.H.K., Aro, M., \& Erskine, J.M. (2003) Foundation literacy acquisition in European orthographies. British Journal of Psychology, 94, 143-174.

Shaywitz, B.A., Shaywitz, S.E., Pugh, K.R., Fulbright, R.K., Constable, R.T., Mencl, W.E., Shankweiler, D.P., Liberman, A.M., Skudlarski, P., Fletcher, J.M., Katz, L., Marchione, K.E., Lacadie, C., Gatenby, C., \& Gore, J.C. (2002) Disruption of posterior brain systems for reading in children with developmental dyslexia Biological Psychiatry, 52, 101-110.

Taft, M. (2001) Processing of orthographic structure by adults of different reading ability. Language and Speech, 44, 351-376.

Tarkiainen, A., Helenius, P., Hansen, P.C., Cornelissen, P.L., \& Salmelin, R. (1999) Dynamics of letter string perception in the human occipitotemporal cortex. Brain, 122, 2119-2132.

Temple, E., Deutsch, G.K., Poldrack, R.A., Miller, S.L., Tallal, P., Merzenich, M.M., \& Gabrieli, J.D.E. (2003) Neural deficits in children with dyslexia ameliorated by behavioral remediation: Evidence from functional MRI. Proceedings of the National Academy of Sciences, 100, 2860-2865.

Treiman, R., Mullennix, J., Bijeljac-Babic, R., \& Richmond-Welty, E.D. (1995) The special role of rimes in the description, use, and acquisition of English orthography. Journal of Experimental Psychology: General, 124, 107-136.

Ventura, P., Kolinsky, R., Brito-Mendes, C., \& Morais, J. (2001) Mental representations of the syllable internal structure are influenced by orthography. Language and Cognitive Processes, 16, 393-418.

Ventura, P., Morais, J., Pattamadilok, C., \& Kolinsky, R. (2004) The locus of the orthographic consistency effect in auditory word recognition. Language and Cognitive Processes, 19, 57-95.

Warrington, E.K., \& Shallice, T. (1980) Word-form dyslexia. Brain, 103, 99-111.

Winchester, I. (1985) Atlantas, Centaurians, and the litron bomb: Some personal and social implications of literacy. In Literacy, language and learning: The nature and consequences of reading and writing (D.R. Olson, N. Torrance, \& A. Hildyard, editors). Cambridge, Mass.: Cambridge University Press.

Ziegler, J.C., \& Ferrand, L. (1998) Orthography shapes the perception of speech: The consistency effect in auditory recognition. Psychonomic Bulletin \& Review, 5, 683-689 . 
Ziegler, J.C., Ferrand, L., \& Montant, M. (2004) Visual phonology: the effects of orthographic consistency on different auditory word recognition tasks. Memory \& Cognition, 32, 732-741.

Ziegler, J.C., Perry, C., Jacobs, A.M., \& Braun, M. (2001) Identical words are read differently in different languages. Psychological Science, 12, 379-384.

Zorzi, M., Houghton, G., \& Butterworth, B. (1998) Two routes or one in reading aloud? A connectionist dual process model. Journal of Experimental Psychology: Human Perception and Performance, 24, 1131-1161.

José Morais

Unité de Recherche en Neurosciences Cognitives

Université Libre de Bruxelles (ULB),

50 Av. F.D. Roosevelt

B-1050 Bruxelles, Belgium

jmorais@ulb.ac.be

Chotiga Pattamadilok

Université Libre de Bruxelles (ULB), Belgium

$\&$ Fonds de la Recherche Scientifique -

F.N.R.S., Belgium

cpattama@ulb.ac.be
Paulo Ventura

Universidade de Lisboa, Portugal

Faculdade de Psicologia e

Ciências da Educação

paulo.ventura@fpce.ul.pt

Régine Kolinsky

Université Libre de Bruxelles (ULB), Belgium \& Fonds de la Recherche Scientifique -

F.N.R.S., Belgium

rkolins@ulb.ac.be 